\title{
A technical review and guide to RNA fluorescence in situ hybridization
}

\author{
Alexander P Young ${ }^{\text {Corresp., } 1}$, Daniel J Jackson ${ }^{2}$, Russell C Wyeth ${ }^{1}$ \\ ${ }^{1}$ Department of Biology, St. Francis Xavier University, Antigonish, NS, Canada \\ ${ }^{2}$ Geobiology, Georg-August Universität Göttingen, Göttingen, Germany \\ Corresponding Author: Alexander P Young \\ Email address: ayoung@stfx.ca
}

RNA-fluorescence in situ hybridization (FISH) is a powerful tool to visualize target mRNA transcripts in cultured cells, tissue sections or whole-mount preparations. As the technique has been developed over time, an ever-increasing number of divergent protocols have been published. There is now a broad selection of options available to facilitate proper tissue preparation, hybridization, and post-hybridization background removal to achieve optimal results. Here we review the technical aspects of RNA-FISH, examining the most common methods associated with different sample types including cytological preparations and whole-mounts. We discuss the application of commonly used reagents for tissue preparation, hybridization, and post-hybridization washing and provide explanations of the functional roles for each reagent. We also discuss the available probe types and necessary controls to accurately visualize gene expression. Finally, we review the most recent advances in FISH technology that facilitate both highly multiplexed experiments and signal amplification for individual targets. Taken together, this information will guide the methods development process for investigators that seek to perform FISH in organisms that lack documented or optimized protocols. 


\section{A technical review and guide to RNA fluorescence in situ hybridization}

2

3 Alexander P. Young ${ }^{1 *}$, Daniel J. Jackson ${ }^{2}$, Russell C. Wyeth ${ }^{1}$

4

$5 \quad{ }^{1}$ Department of Biology, St. Francis Xavier University, Antigonish, NS, Canada

6 2Department of Geobiology, Georg-August University of Göttingen, Göttingen, Germany

7

$8 *$ Corresponding author

9 Alexander P. Young

102320 Notre Dame Ave., Antigonish, Nova Scotia, B2G 1Z3, Canada

11 Email address: ayoung@stfx.ca 


\section{Abstract}

13 RNA-fluorescence in situ hybridization (FISH) is a powerful tool to visualize target mRNA

14 transcripts in cultured cells, tissue sections or whole-mount preparations. As the technique has

15 been developed over time, an ever-increasing number of divergent protocols have been

16 published. There is now a broad selection of options available to facilitate proper tissue

17 preparation, hybridization, and post-hybridization background removal to achieve optimal

18 results. Here we review the technical aspects of RNA-FISH, examining the most common

19 methods associated with different sample types including cytological preparations and whole-

20 mounts. We discuss the application of commonly used reagents for tissue preparation,

21 hybridization, and post-hybridization washing and provide explanations of the functional roles

22 for each reagent. We also discuss the available probe types and necessary controls to accurately

23 visualize gene expression. Finally, we review the most recent advances in FISH technology that

24 facilitate both highly multiplexed experiments and signal amplification for individual targets.

25 Taken together, this information will guide the methods development process for investigators

26 that seek to perform FISH in organisms that lack documented or optimized protocols. 


\section{Introduction}

29 Fluorescence in situ hybridization (FISH) is a powerful tool to visualize target DNA sequences or mRNA transcripts in cultured cells, tissue sections or whole-mount preparations. FISH

31 functions via the principles of nucleic acid thermodynamics whereby two complementary strands

32 of nucleic acids readily anneal to each other under the proper conditions to form a duplex

33 (RNA:RNA or DNA:DNA), known as a hybrid (Felsenfeld \& Miles, 1967). Under energetically

34 favourable conditions, strands of RNA and DNA can also anneal to form DNA:RNA hybrids

35 (Rich, 1959, 1960; Milman, Langridge \& Chamberlin, 1967). These phenomena have facilitated

36 the development of techniques that use either DNA or RNA probes to bind to DNA or RNA

37 targets within a biological sample, a method broadly known as in situ hybridization (ISH). The

38 earliest ISH protocols relied on radioactive probes that were costly, required long exposure

39 times, and were hazardous to human health (Gall \& Pardue, 1969; Pardue \& Gall, 1969). Probes

40 that relied on fluorophores instead of radioactive isotopes were later developed and could be

41 directly detected with fluorescence microscopy. Methods that employed these probes became

42 known as fluorescence in situ hybridization (FISH; Rudkin \& Stollar, 1977). As FISH can be

43 used to target DNA, modern FISH protocols can label positions of genes on chromosomes,

44 diagnose diseases, and identify microorganisms (Kempf, Trebesius \& Autenrieth, 2000; Wiegant

45 et al., 2000; Hicks \& Tubbs, 2005). However, FISH has also been developed to target RNA and

46 thus visualize gene expression in situ, herein referred to as RNA-FISH (Singer \& Ward, 1982).

47 More recently, computational and imaging technology has further driven the development of

48 RNA-FISH to allow for the visualization and semi-automated quantification of individual

49 messenger RNA (mRNA) transcripts (Femino et al., 1998; Levsky et al., 2002; Raj et al., 2006,

50 2008). The use of RNA-FISH to visualize individual mRNA molecules in this fashion is 
51 currently known as single-molecule FISH (smFISH; Femino et al., 1998). Ultimately, there are

52 several derivations of the original ISH method that have diverged to localize either DNA or RNA

53 molecules with one of many detection methods. In this review, we focus on RNA-FISH methods.

54

55 As the number of FISH-based methods has increased, the number of published reagents, probe

56 types, and detection methods have also expanded. This rise in options has increased the

57 complexity faced by a researcher when developing a new FISH protocol or attempting to adapt

58 an established protocol for use with a non-conventional sample type. Furthermore, published

59 protocols rarely clarify which components are essential, and which are "traditional" elements

60 inherited from previous iterations of a protocol. Thus, for a newcomer seeking to repurpose a

61 published protocol, it is often unclear which steps of a protocol may be critical to its success or

62 which steps could be removed for their own purposes. Here we review the technical aspects of

63 RNA-FISH, including but not limited to smFISH. Based on a critical analysis of some leading

64 published methods, we summarize the technique with respect to commonly used reagents for

65 tissue preparation, hybridization, and post-hybridization washing and provide explanations of the

66 functional roles for each reagent. The purpose of this review is to draw common ISH variants

67 and their rationales together to equip users with the knowledge to develop novel applications of

68 RNA-FISH for unexplored sample types. Thus, we present a broad survey of published RNA-

69 FISH protocols to educate new users and streamline the methods development process for both

70 experienced and new investigators. It is worth noting the substantial overlap between many

71 published ISH and FISH protocols with respect to tissue preparation, hybridization, and post-

72 hybridization. We have drawn information from a broad selection of protocols which could also 
73 benefit the development of non-fluorescent (also known as chromogenic or colorimetric) ISH

74 protocols (excluding probe generation and detection).

75

76 Survey methodology

77 To compare differences in modern FISH methodologies (tissue preparation, hybridization, and 78 post-hybridization), the literature was broadly surveyed using PubMed and Google Scholar to 79 search terms including "FISH", "fluorescent", "fluorescence", and "in situ hybridization". We 80 also cross-referenced each article to identify further relevant resources from the published

81 literature. Manuscripts that included sufficiently detailed methods were selected for comparison.

82 Generally, manuscripts from the last 10 years (after 2009) were preferred to reflect modern 83 methods, however, we also include early works that heavily influenced the development of the 84 technique. To support discussion of the commonly used reagents, we searched for manuscripts 85 that specifically explained the mechanistic underpinnings of the reagents.

86

87 The historical development of RNA-FISH

88 The method of labeling strands of nucleic acids in situ has undergone substantial development

89 (Fig. 1). The earliest ISH techniques were documented in a pair of companion papers by Gall and

90 Pardue (Gall \& Pardue, 1969; Pardue \& Gall, 1969). Gall \& Pardue (1969) used RNA-based

91 probes to label DNA in oocytes of the toad Xenopus. Pardue \& Gall (1969) used DNA-based

92 probes to label DNA in the same cells from the same species. In both cases, these probes

93 required autoradiography for visualization. The first fluorescence in situ detection of DNA with

94 indirect immunofluorescence was performed by Rudkin \& Stollar (1977) to label polytene

95 chromosomes in Drosophila melanogaster. The authors used RNA probes with hapten-labeled 
96 nucleotides that could be targeted with rhodamine-labeled antibodies and subsequently

97 visualized with a fluorescence microscope. These probes circumvented many of the

98 disadvantages associated with autoradiography (Bauman et al., 1980; Kislauskis et al., 1993).

99 Direct fluorescence in situ detection (of DNA) without the need for antibodies was later

100 performed by Bauman et al. (1980). The authors labeled mitochondrial DNA in the insect

101 trypanosome Crithilia luciliae using an RNA probe with rhodamine directly incorporated into

102 the probe (RNA was oxidized with $\mathrm{NaIO}_{4}$ and coupled to tetramethyl rhodamine thio-

103 semicarbazide).

104

105 Although RNA-based probes had been used to this point, FISH had only been used to label

106 DNA. Singer \& Ward (1982) performed the first true RNA-FISH to visualize actin mRNA in a

107 culture of chicken skeletal muscle. The authors used DNA probes labeled with biotin as a hapten

108 (biotinated dUTP was incorporated via nick-translation). Following hybridization, these probes

109 were targeted with primary antibodies and then with secondary anti-biotin rhodamine-conjugated

110 antibodies. The secondary antibody labeling allowed Singer and Ward to produce stronger

111 fluorescence compared to the direct detection method of Bauman et al. (1980). In the early

112 development of RNA-FISH, probes had relied on either one fluorophore per probe molecule (and

113 thus per hybridized transcript) or signal amplification using immunofluorescence. Neither of

114 these methods produced adequately strong signals at a fixed fluorophore ratio per hybridized

115 transcript that allows for absolute transcript quantification. Thus, only relative quantification of

116 gene expression was possible.

117 
118 Singer and colleagues later introduced the method of smFISH using multiple probes that were

119 directly labeled with several Cy3 molecules per probe molecule. This method was sensitive

120 enough to resolve individual mRNA transcripts (Femino et al., 1998). Due to the close proximity

121 of fluorophores of the heavily labeled probe, the fluorophores underwent self-quenching

122 (Randolph \& Waggoner, 1997). This increased variability and interfered with quantification of

123 the number of probe molecules bound to each transcript (Femino et al., 1998). In subsequent

124 iterations of smFISH protocol development, the introduction of greater numbers of shorter

125 singly-labeled probes resulted in labeling that was precise enough to allow for semi-automated

126 quantification using companion image analysis software (Raj et al., 2006; Raj et al., 2008; Raj \&

127 van Oudenaarden, 2009; Taniguchi et al., 2010; Lyubimova et al., 2013). Raj et al. (2006, 2008)

128 used a series of 20-mer oligonucleotide probes to collectively span the length of the transcripts of

129 interest. Each probe was tagged with a single Alexa 594 fluorophore at the 3'-terminus to yield a

130 predictable number of fluorophores per transcript. Raj et al. (2008) found that this approach

131 achieved a similar sensitivity in labeling individual transcripts compared to the method of

132 Femino et al. (1998), however, the newer method could more unambiguously discriminate

133 between signal and background and had a simplified probe synthesis process. In parallel

134 developments, other protocols were established using multiple nucleic acid-based probes with

135 different fluorophores to measure the expression of multiple genes within individual cells

136 (Levsky et al., 2002; Raj \& van Oudenaarden, 2009). smFISH has also been paired with

137 immunofluorescence and flow cytometry to simultaneously measure mRNA and protein

138 abundance (Yoon, Pendergrass \& Lee, 2016; Arrigucci et al., 2017; Eliscovich, Shenoy \&

139 Singer, 2017). 


\section{Technical aspects of FISH}

142 Many permutations of the FISH methodology exist for a variety of niche purposes (Volpi and

143 Bridger 2008). Despite the range of techniques available, there is a core set of processing steps

144 which are common to most: tissue preparation (pre-hybridization), hybridization, and washing

145 (post-hybridization). These processes are essential to a FISH protocol, and each requires specific

146 reagents to be effective. Generally, the required reagents are similar for cytological, histological,

147 and whole-mount preparations. However, there are some differences which are highlighted

148 below. Note that the design and synthesis of a probe or multiple probes is also a critical phase of

149 any ISH experiment that we will not discuss in depth here. However, characteristics such as the

150 GC content, the propensity to form secondary structures, the overall length and specificity and

151 probe quantity and quality must be considered (Kucho et al., 2004). It should be noted here that

152 the use of purely synthetic oligonucleotide probes and short PCR-derived probes are gaining

153 popularity over in vitro transcription-derived probes that span the majority of a transcript.

154 Synthetic probes give the user great control over probe characteristics that affect hybridization

155 (Beliveau et al., 2012, 2018; Bienko et al., 2013) and omit the standard practice of cloning the

156 target gene which would delay the FISH process.

157

158 Tissue preparation and permeabilization

159 Tissue preparation is one of the most critical aspects of a FISH protocol. Tissue preparation

160 typically comprises both fixation and tissue permeabilization, and the balance of these is

161 important in determining the degree of probe penetration as well as the morphological integrity

162 of the sample. Prior to fixation, and critical for some species and sample types while less

163 important for others, is the issue of relaxation of the sample of interest; a clear FISH signal can 
164 be obscured or rendered uninterpretable if it is concealed by a contracted morphology. Muscle

165 relaxants are extremely species-specific and beyond the scope of this review, however an

166 adequately relaxed tissue preparation (especially for whole-mounts) will make the visualization

167 and interpretation of any signal significantly easier. We encourage the reader to survey the

168 literature for appropriate relaxants for their species of interest. The most common fixatives are

$1694 \%$ formaldehyde or paraformaldehyde in phosphate buffered saline (PBS; Nakamura,

170 Nakamura \& Hamada, 2013; Neufeld et al., 2013; Kernohan \& Bérubé, 2014; Shiura et al., 2014;

171 Oka \& Sato, 2015; Thiruketheeswaran, Kiehl \& D’Haese, 2016). Formaldehyde is a crosslinking

172 fixative that forms covalent links between macromolecules such as lipids, peptides and DNA;

173 this creates a mesh inside the cells or tissues to hold their components in place and minimize

174 enzymatic degradation over time (Eltoum et al., 2001). Paraformaldehyde (PFA) solutions

175 produced from a powder will contain pure fixative, however, prepared 4\% PFA solutions will

176 produce polymers over time and become less effective as the polymers precipitate from the

177 solution (Thavarajah et al., 2012). Thus, PFA solutions should be made fresh for each

178 experiment. Alternatively, commercial formalin contains $37 \%$ monomeric formaldehyde in water

179 and is supplemented with $10 \%$ methanol as a stabilizer to prevent polymer formation. Thus, a

180 1:10 dilution of commercial formalin solution is a common substitute for 4\% PFA that does not

181 require fresh preparation for each experiment (Thavarajah et al., 2012).

182

183 Fixation protocols are generally consistent among cytological, histological, and whole-mount

184 preparations, although whole mounts generally require longer treatments to ensure complete

185 penetration of the fixative. Fixation protocols often consist of a treatment with $4 \%$ PFA or

186 formaldehyde in PBS for varied lengths of time and temperatures (Table S1). These examples, 
187 and the link between sample size and density (larger and more dense samples need longer

188 fixation) can provide some scope when estimating a fixation duration for other sample types.

189 Optimal fixation of planarian worms is achieved with $4 \%$ formaldehyde for 20 minutes (Pearson

190 et al., 2009; Rink, Vu \& Alvarado, 2011). For bacterial species or eukaryotic cells, 4\% PFA is

191 used to fix cells for as little as 10 minutes or as much as 90 minutes (Shaffer et al., 2013; Skinner

192 et al., 2013; Chen et al., 2015; Wang et al., 2015; Aistleitner et al., 2018; Cardinale et al., 2018;

193 Rocha, Almeida \& Azevedo, 2018). Fruit fly (Drosophila melanogaster) embryos are typically

194 fixed in 4\% PFA for 20 - 30 minutes (Hauptmann et al., 2016; Jandura et al., 2017; Little \&

195 Gregor, 2018; Szabo et al., 2018). Zebrafish (Danio rerio) embryos and the annelid Platynereis

196 dumerilii can be suitably fixed in 4\% PFA for 2 hours at room temperature (Jékely \& Arendt,

197 2007; Steinmetz et al., 2011) but can alternatively be fixed overnight at $4^{\circ} \mathrm{C}$ (Oxtoby \& Jowett,

198 1993; Lauter, Söll \& Hauptmann, 2011a,b; Marra et al., 2017). Arms of the brittle star

199 (Amphiura filiformis) are also sufficiently fixed in $4 \%$ PFA overnight at $4^{\circ} \mathrm{C}$. Embryos of the

200 brachiopods Terebratalia transversa and Novocrania anomala should be fixed in 4\%

201 formaldehyde for 4 hours (Schiemann et al., 2017; Gąsiorowski \& Hejnol, 2019). The starlet sea

202 anemone (Nematostella vectensis) and an acoelomorph worm (Convolutriloba longifissura) have

203 been successfully fixed for ISH with 3.7\% formaldehyde supplemented with $0.3 \%$

204 glutaraldehyde which is another strong cross-linking agent (Finnerty et al., 2003; Martindale,

205 Pang \& Finnerty, 2004; Hejnol \& Martindale, 2008). Note, however, that glutaraldehyde is

206 known to increase autofluorescence, at least with immunohistochemistry protocols. Whole

207 mouse brains are often fixed in 4\% PFA for up to 6 hours at room temperature or overnight at

$2084^{\circ} \mathrm{C}$, although fixation of brain tissue is recommended not to exceed 24 hours (Kernohan \&

209 Bérubé, 2014; Kasai et al., 2016; Lanfranco et al., 2017; Hua et al., 2018). 
211 As an alternative to formaldehyde, some protocols employ alcohol-based fixation using either

212 ethanol (Schurter, LeBrun \& Harrison, 2002) or methanol (Legendre et al., 2013). Ethanol and

213 methanol are coagulant fixatives that replace free water in the tissue to dehydrate cells and

214 destabilize hydrophobic and hydrogen bonds (Eltoum et al., 2001). Alcohol-based fixation is

215 common for cultured cells and ice-cold $\left(-20^{\circ} \mathrm{C}\right)$ ethanol and methanol have been used to fix

216 multiple cultured cell lines in as little as 10 minutes (Shaffer et al. 2013). To fix tissue sections or

217 whole-mounts, alcohol is commonly combined with other fixatives such as formaldehyde

218 (Finnerty et al., 2003; Martindale, Pang \& Finnerty, 2004; Hejnol \& Martindale, 2008; Pearson

219 et al., 2009). Although methanol has been used successfully with immunofluorescence (Levitt

220 and King, 1987), methanol has a propensity to disrupt native protein structure and is generally

221 not recommended for use in multiplex FISH and immunohistochemistry (Fowler et al., 2011).

222 Methanol will strip membrane lipids to improve permeability (Hoetelmans et al., 2001) and

223 ethanol can strip the external wax and lipids from plant tissues (Bleckmann \& Dresselhaus,

224 2016). Thus, if cross-linking is also desired, formalin may improve tissue permeability over

225 paraformaldehyde due to the added methanol. For example, fixative solutions that contain

226 alcohol and formaldehyde improve permeability in gram-positive bacterial preparations and may

227 retain higher DNA quality in cytological preparations (Manz et al., 1994; Shaffer et al., 2013).

229 Beyond the choice of fixative, fixation temperature can also have a substantial impact on the

230 final tissue quality (Fox et al., 1985; Thavarajah et al., 2012). With the use of formaldehyde, heat

231 can accelerate the fixation process; although heat also increases the release of formaldehyde

232 fumes which are hazardous to human health (Fox et al., 1985; Titford, 2001). Additionally, heat 
233 can denature proteins and cause a loss of antigenicity which would negatively affect multiplex

234 FISH and immunohistochemistry (Fowler et al., 2011). For nucleic acid visualization, reduced

235 temperatures of $4^{\circ} \mathrm{C}$ have been shown to preserve RNA throughout the fixation process

236 (Bussolati et al., 2011). Additionally, ice-cold solutions of alcohol fixatives are recommended as

237 the reduced temperatures will reduce the risk of over-permeabilization and subsequent leakage of 238 target molecules.

240 Following fixation, samples are generally permeabilized to allow for proper penetration of

241 hybridization reagents. Detergent treatment of fixed tissue is commonly employed at a

242 concentration of $0.1 \%$ as it substantially improves permeability of the tissues via disruption of

243 cellular membranes. The use of Tween-20 is common but other detergents including sodium

244 dodecyl sulfate (SDS) and Triton X-100 can also be used. The detergent 3-[(3-

245 cholamidopropyl)dimethylammonio]-1-propanesulfonate (CHAPS) is commonly used as an 246 additive detergent to multiplex FISH with immunofluorescence as it effectively protects the 247 native structure of proteins (Meyer, Garzia \& Tuschl, 2017; Sepsi et al., 2018). Whole-mount

248 preparations generally require stronger detergent treatments compared to cytological

249 preparations or sectioned tissue, thus, a more aggressive detergent treatment such as $4 \%$ Triton 250 X-100 can be effective in whole-mounts (Croll et al., 1999).

251

252 Treatment with a nonspecific protease such as proteinase $\mathrm{K}$ will permeabilize the tissues after

253 fixation and can also release target nucleic acid molecules from bound proteins (such as RNA

254 binding proteins), making them more accessible for hybridization. There is generally an inverse

255 relationship between fixation time and the strength of the proteinase treatment as more highly 
256 fixed tissues will require a stronger protease digestion to become permeable to the probe. A

257 protease treatment is not always necessary for bacterial or eukaryotic cells as a detergent is

258 usually sufficient, however, a brief treatment with a dilute solution of proteinase K should be

259 considered if probe penetration is the suspected cause of an issue (Carr et al., 2005). Zebrafish

260 embryos are treated with $10 \mu \mathrm{g} / \mathrm{mL}$ proteinase $\mathrm{K}$ in PBST for $2-20$ minutes depending on the

261 age (Oxtoby \& Jowett, 1993; Marra et al., 2017). The same treatment is also recommended for

262 snail embryos as well as whole-mount planarian worms and is sometimes applied to fruit fly

263 embryos, although several other permeabilization strategies including acetone are also frequently

264 used for Drosophila (Paré et al., 2009; Pearson et al., 2009; Jackson, Herlitze \& Hohagen, 2016;

265 Hauptmann et al., 2016; Trcek et al., 2017). Some protocols call for brain sections to be treated

266 with proteinase $\mathrm{K}$, however, many protocols omit this step as permeability is less of an issue with

267 sectioned material (Kasai et al., 2016; Hua et al., 2018). The proteinase K treatment will require

268 careful optimization as too little digestion will prevent probe penetration whereas too much

269 digestion will destroy the morphology of the tissue and lead to increased background (Tessmar-

270 Raible et al., 2005; Bleckmann \& Dresselhaus, 2016). As the degree of permeabilization with

271 proteinase $\mathrm{K}$ can be a critical factor in the success of a FISH experiment, we recommend the use

272 of accurately and consistently assayed batches of proteinase K enzyme such as supplied by New

273 England Biolabs (Catalog: P8107S). As an alternative to proteinase K, pepsin has also been used

274 to achieve more mild digestion of the tissue. Pepsin is preferred for cultured cells (Buxbaum, Wu

$275 \&$ Singer, 2014) and tissue sections (Moorman et al., 2001; Teng et al., 2017) but potentially

276 could be adapted to whole embryos. A treatment of $1 \mathrm{mg} / \mathrm{mL}$ pepsin in $0.01 \mathrm{~N} \mathrm{HCl}$ is a common

277 treatment, although the treatment length varies from 30 seconds to 10 minutes depending on the

278 sample type (Moorman et al., 2001; Buxbaum, Wu \& Singer, 2014; Teng et al., 2017). 
280 Further permeabilization treatments are available as an alternative or an addition to protease

281 treatments. A treatment of $1 \mathrm{M} \mathrm{HCl}$ at $37^{\circ} \mathrm{C}$ for $30-50$ minutes is effective to improve

282 permeability of mycolic-acid-containing bacterial cells whereas other bacteria (including

283 Escherichia coli) can be permeabilized in only 10 minutes (Macnaughton, O’Donnell \& Embley,

284 1994). The addition of Triton X-100 or other detergent directly to the fixative in the initial

285 fixation protocol has also been used to improve the permeability of bacterial cells through its 286 interaction with cell envelope lipid molecules (Jackson, Herlitze \& Hohagen, 2016; Rocha,

287 Almeida \& Azevedo, 2018). Protease-free detergent-based methods have also been successful

288 for permeabilization of Drosophila embryos (Boettiger \& Levine, 2013). Zebrafish embryos that

289 are stored in methanol can be treated with $2 \% \mathrm{H}_{2} \mathrm{O}_{2}$ for 20 minutes at room temperature to

290 improve permeability (Lauter, Söll \& Hauptmann, 2011b). This $\mathrm{H}_{2} \mathrm{O}_{2}$ treatment can also quench

291 endogenous peroxidase activity and bleach tissues to reduce background in horseradish

292 peroxidase-based assays (Marra et al., 2017). Organic solvents such as acetone have been used as

293 an alternative to protease digestion of fragile embryos, and this method can also retain

294 antigenicity for immunohistochemistry (Nagaso et al. 2001). In the preparation of whole-mounts

295 with particularly tough integument, a digestion with $0.25 \%$ collagenase can be incorporated to

296 improve permeability of dermal layers (Wyeth \& Croll, 2011). Ultimately, careful optimization

297 of the balance between fixation (strength, length and temperature thereof) and a proteinase based 298 permeabilization is necessary to achieve a consistently high signal to noise ratio.

299

\section{Hybridization}


301 For efficient and complete hybridization of probe to target, the optimal environment must be

302 provided. The hybridization reaction can contain an array of different components (Table S1). In

303 addition to the tissue, most documented hybridization solutions comprise a saline-sodium citrate

304 buffer (SSC) with formamide, vanadyl-ribonucleoside complex (VRC), dextran sulfate, bovine

305 serum albumin (BSA), competitor tRNA or DNA, and the probe (Pinkel et al., 1988; Singer,

306 1998; Shaffer et al., 2013; Kernohan \& Bérubé, 2014; Oka \& Sato, 2015). Alternative

307 components include Denhardt's solution, ethylenediaminetetraacetic acid (EDTA), and Tween-

30820 (Langenbacher et al., 2015; Parker et al., 2019). In addition to the recipe of the hybridization

309 solution, there are several reaction conditions that must be considered, including salt

310 concentration, $\mathrm{pH}$, and the temperature and duration of the hybridization reaction.

312 Formamide reduces the free energy of binding of nucleic acid strands to allow hybridization to

313 take place at lower temperatures without a loss in specificity, thus improving structural

314 preservation of the tissue (McConaughy, Laird \& McCarthy, 1969; Bauman et al., 1980; Blake \&

315 Delcourt, 1996; Fontenete et al., 2016). As formamide stabilizes free bases and single-stranded

316 DNA in solution, the melting temperature of DNA is decreased in a linear fashion by $2.4-2.9^{\circ} \mathrm{C}$

317 per mole of formamide in the hybridization buffer (Blake \& Delcourt, 1996). Formamide

318 generally composes between $10-50 \%$ of the final volume of the hybridization buffer, but this

319 range may be exceeded under specific circumstances (Table S1). Formamide is a toxic substance

320 and, therefore, proper safety precautions must be made to avoid inhalation and direct contact

321 with formamide (Warheit et al., 1989). Protocols that use safer alternatives to formamide, such as

322 urea (Sinigaglia et al., 2018) have been developed but have yet to gain popularity (Volpi, 2017).

323 
324 VRC is an RNase inhibitor that is used to protect RNA-based probes or targets from enzymatic

325 degradation (Berger \& Birkenmeier, 1979; Frazier \& Champney, 2012). VRC is typically added

326 to the hybridization buffer at a final concentration of $10 \mathrm{mM}$ as a precautionary measure. VRC is

327 not compatible with solutions that contain EDTA as an equimolar concentration of a chelating

328 agent will sequester the cations required for proper VRC function (Puskas et al., 1982). An

329 RNase inhibitor is not absolutely necessary for successful ISH, but one should be considered if

330 RNase contamination is a suspected problem.

331

332 Dextran sulfate is an anhydroglucose polymer that absorbs water molecules to reduce the free

333 water in the reaction. This forces the probe and the target closer together, an effect referred to as

334 molecular crowding, which enhances the rate of hybridization of the probe to the target

335 (Lederman, Kawasaki \& Szabo, 1981). Dextran sulfate can also improve fluorescent signals (van

336 Gijlswijk et al., 1996; Franks et al., 1998). Dextran sulfate is a synthetic analogue of heparin

337 which can also be used in the hybridization buffer and has also been reported to reduce

338 background signal (Singh \& Jones, 1984). Dextran sulfate is most often employed at a

339 concentration of 50 to $100 \mathrm{mg} / \mathrm{mL}$ (Table S1; Singer \& Ward, 1982; Oka \& Sato, 2015; Parker et

340 al., 2019).

341

342 BSA is used as a blocking agent to reduce background signal and thus improve the contrast of

343 the probe (Choo, 2008). BSA blocks nonspecific binding of probe molecules to nucleic acid

344 binding sites on proteins within the tissue as it can saturate the binding sites prior to the

345 introduction of the probe. The use of BSA as a blocking agent may be especially important when 
346 using antibody-based detection methods. BSA is generally used at a concentration of $1 \mathrm{mg} / \mathrm{mL}$

347 (Thiruketheeswaran, Kiehl \& D’Haese, 2016) up to $10 \mathrm{mg} / \mathrm{mL}$ (Singer \& Ward, 1982)

348

349 Finally, sheared salmon sperm DNA or tRNA from E. coli or yeast is usually included in the 350 hybridization buffer. The purpose of competitive nucleic acids is also to saturate nonspecific

351 binding sites for probes to reduce background. Additionally, the competitor tRNA may protect

352 target mRNA molecules via nonspecific blocking of RNase molecules that may have

353 contaminated the solution. The optimal concentration of tRNA within the hybridization buffer

354 should be empirically determined as it may vary widely depending on the tissue sample and the

355 probe (Table S1; Langenbacher et al., 2015; Liu et al., 2019).

356

357 There are several alternative hybridization buffer components that can be used to facilitate an

358 optimal hybridization environment. Denhardt's solution is a broad blocking reagent composed of

359 BSA, Ficoll type 400 and polyvinylpyrrolidone that can be used in place of BSA alone. EDTA is

360 a chelating agent that can be added to a final concentration of $10 \mathrm{mM}$ to remove free divalent

361 ions such as magnesium. As EDTA can inactivate the VRC, these components are mutually

362 exclusive.

363

364 When the reagent recipe has been established to create a supportive hybridization solution, the

365 hybridization conditions must also be determined to facilitate optimal hybridization. We believe

366 attention should be first given to the following parameters regarding hybridization: salt

367 concentration, $\mathrm{pH}$, hybridization temperature, and duration of hybridization. Optimal

368 hybridization will occur under conditions that allow the hybridization of the probe to the target 
369 but prevent the formation of nonspecific hybrids. Conditions that promote the sole formation of

370 highly stable hybrids are known as highly stringent conditions whereas more permissive

371 conditions that may allow the formation of nonspecific hybrids are considered less stringent. The

372 stringency of the hybridization is affected by the concentration of salt in the hybridization

373 solution (lower concentrations are more stringent) as well as the hybridization temperature

374 (higher temperatures are more stringent). It is most common to keep the salt concentration

375 constant ( $750 \mathrm{mM} \mathrm{NaCl}, 87.5 \mathrm{mM}$ sodium citrate), with $\mathrm{pH}$ roughly between 7.0 and 8.5 , and

376 simply adjust the hybridization temperature to achieve the ideal stringency (Pearson et al., 2009;

377 Zhang et al., 2012; Jackson, Herlitze \& Hohagen, 2016). An initial denaturation step of $75^{\circ} \mathrm{C}$ for

37810 minutes can be used to denature all target and probe RNA facilitate hybridization, the sample

379 is then immediately adjusted to the designated hybridization temperature (Jékely \& Arendt,

380 2007; Jackson, Herlitze \& Hohagen, 2016). The optimal hybridization temperature is dependent

381 on the length and composition of the probe, with higher temperatures being more stringent and

382 less conducive to hybridization. Although the hybridization temperature should be empirically

383 optimized for every probe individually, short oligonucleotide probes (20-50 nucleotides)

384 typically require lower hybridization temperatures of $37^{\circ} \mathrm{C}$ whereas longer riboprobes of $1000+$

385 nucleotides may hybridize at temperatures $>55^{\circ} \mathrm{C}$ (Pearson et al., 2009; Jackson, Herlitze \&

386 Hohagen, 2016; Fontenete et al., 2016). Generally, the hybridization step cannot be over-

387 incubated and usually involves determining the minimum duration after which labeling no longer

388 improves. Thus, an extended hybridization should be performed to allow probes to completely

389 occupy available targets. Most often, $12-24$ hours is sufficient, regardless of the probe type

390 (Carleton et al., 2014; Jackson, Herlitze \& Hohagen, 2016; Meyer, Garzia \& Tuschl, 2017;

391 Jandura et al., 2017). Rapid hybridization has been achieved in cultured cells in as little as five 
392 minutes with the Turbo FISH method (Shaffer et al., 2013), but this is not a prudent point of

393 entry for new protocols, especially for whole-mount material. Ultimately, salt concentration,

394 hybridization temperature, and hybridization duration can be adjusted to create the optimal

395 hybridization conditions with enough stringency to exclude non-specific labeling.

396

397

\section{Post-hybridization treatments}

398 The purpose of the post-hybridization washes is to separate nonspecific hybrids and remove

399 unbound probe molecules from the tissue to minimize background signal. Samples are typically

400 subjected to increasingly stringent washes in SSC buffer containing formamide and a detergent

401 (Table S1; Jackson, Herlitze \& Hohagen, 2016; Thiruketheeswaran, Kiehl \& D’Haese, 2016).

402 Increased stringency can be achieved through sequential washes with incrementally reduced salt

403 concentrations while the wash temperature is matched to the hybridization temperature

404 (Martindale, Pang \& Finnerty, 2004; Hejnol \& Martindale, 2008; Jackson, Herlitze \& Hohagen, 405 2016; Schiemann et al., 2017; Gąsiorowski \& Hejnol, 2019). At the end of washing, the goal is

406 to allow only the specific and stable hybrids to remain. A wash progression that finishes with a

407 higher concentration of salt (or at a lower temperature, i.e. lower stringency) will be less likely to 408 denature and remove nonspecific hybrids, but also may preserve greater intensity of specific 409 labeling.

410

411 In addition to nonspecific hybrids, autofluorescence and excessive background are issues that

412 can diminish the visibility of true signal and influence the interpretation of the results. Treatment 413 with $0.1 \%$ Sudan Black B in $70 \%$ ethanol is effective to minimize autofluorescence in sectioned 414 brain tissue as well as cultured cells (Oliveira et al., 2010; Qi et al., 2017). If background signal 
415 is an issue, tissues can also be acetylated with $0.3 \%$ acetic anhydride in triethanolamine for 5 -

41610 minutes (Jackson, Herlitze \& Hohagen, 2016). This acetylation blocks positively charged

417 proteins and amine groups (exposed during enzymatic permeabilization) in the tissue that could

418 otherwise engage in electrostatic interactions with negatively charged probes.

419

420 The final process prior to visualization of results is tissue clearing to prevent lateral light

421 scattering within the tissue, clearing becomes more critical with physically larger specimens

422 (Richardson \& Lichtman, 2015). Common methods of tissue clearing may involve either

423 dehydration or hyperhydration of the tissue sample. An organic solvent-based method of clearing

424 via a two-to-one mixture of benzyl benzoate and benzyl alcohol has been successfully used to

425 visualize whole snail embryos (Jackson, Herlitze \& Hohagen, 2016), however, the tissue must

426 first be dehydrated with a graded series of ethanol. One potential issue with solvent-based

427 clearing is that the dehydration process can cause substantial shrinkage of tissues (Richardson \&

428 Lichtman, 2015). Other methods of clearing that involve hyperhydration include the formamide-

429 based ClearT (Kuwajima et al., 2013) as well as the urea-based CUBIC (Susaki et al., 2014;

430 Tainaka et al., 2014). Methods of hyperhydration often involve large quantities of detergent and

431 are most suitable when it is desirable to remove the majority of lipids from the tissue sample. A

432 more advanced method of tissue clearing involves the use of anchor probes to fix the hybrids

433 within a polymer matrix with subsequent digestion of non-RNA material (Moffit et al., 2016b),

434 however, this technique is most suitable for highly multiplexed FISH experiments.

435

436 Probe selection and optimization for FISH 
437 Probes are nucleic acid strands that may be composed of DNA, cDNA or RNA; they may be

438 single-stranded or double-stranded and may vary in length from 20 bases to over 1500 bases.

439 Regardless of the probe type, the sequence of the probes must be complementary to the target

440 sequence to ensure proper hybridization. Probes can be modified with a fluorophore directly

441 attached to the probe to be detectable with fluorescence microscopy, or fluorophores may be

442 covalently linked to an antibody that binds to an antigen incorporated into the probe (Fig. 2).

444 Despite the advantages and increasing popularity of chemically synthesized short probes

445 (employed for example in smRNA-FISH), single-stranded RNA probes (riboprobes) of 500 -

4461500 bases are commonly employed as they are inexpensive and simple for a standardly

447 equipped molecular biology laboratory to produce. Such riboprobes are typically generated

448 through in vitro transcription of a target sequence that has been cloned. In this way target DNA

449 sequences with flanking RNA polymerase promoters can be used with an appropriate RNA

450 polymerase to produce single-stranded complementary RNA probes. Secondary detection is most

451 common with riboprobes as nucleotides tagged with hapten molecules, such as digoxigenin, can

452 be easily incorporated into the transcription reaction. The hapten molecules in the transcribed

453 probe are then subsequently targeted by fluorophore-bound antibodies (Fig. 2). One advantage of

454 riboprobes (rather than DNA-based probes) is that an RNase treatment can follow the post-

455 hybridization step to reduce background. This is only appropriate with riboprobes as RNA:RNA

456 hybrids are unaffected by RNases whereas DNA:RNA hybrids will be degraded (Keller \&

457 Crouch, 1972; Donà \& Houseley, 2014). Note, however, that unintentional RNase contamination

458 earlier in the protocol will be detrimental as single-stranded riboprobes are sensitive to RNases

459 prior to hybridization. 
461 The other prominent probe type in modern FISH protocols is the oligonucleotide probe - a

462 cocktail of short single-stranded synthetic DNA probes that collectively span the length of the

463 target (Fig. 2; Femino et al., 1998; Raj et al., 2008; Zenklusen \& Singer, 2010). Each individual

464 probe molecule can be labeled with a fluorophore on the 5' end, the 3 ' end, or both ends. A

465 broad selection of fluorophores are available including Cy3, Cy5, Alexa fluor (Invitrogen), and

466 Quasar (LGC Biosearch Technologies) depending on the desired absorption/emission spectra,

467 budget, or personal preference. Oligonucleotide probes can be advantageous for particularly

468 challenging tissues as the small probes can penetrate the tissue more efficiently. Furthermore, as

469 each oligonucleotide probe binds to the target, the transcript will relax and facilitate the

470 hybridization of additional probe molecules (Baker, 2012). Oligonucleotides also have the

471 highest specificity possible as they are less tolerant of mismatches that lead to nonspecific

472 binding (Hougaard, Hansen \& Larsson, 1997; Insam, Franke-Whittle \& Goberna, 2009). One

473 aspect of oligonucleotide probes that may deter new users is the level of difficulty associated

474 with their production, or the high cost associated with outsourcing through a commercial supplier

475 (Raj et al. 2008; Zenklusen \& Singer, 2010).

476

477 Controls for an in situ hybridization experiment

478 An often overlooked aspect of FISH experiments is how to employ controls to detect false

479 positive results and to ensure that staining patterns represent genuine biological signal; if a

480 staining pattern is observed following a FISH experiment, it may indicate successful

481 hybridization, but it could also be the result of non-specific binding of the probe. Additionally, a

482 lack of observable signal could mean that the mRNA target is not expressed, but it may also 
483 indicate a technical issue with the protocol despite the presence of the target. We would

484 encourage creativity in carefully designing control experiments to identify the causes of

485 undesired or absent results. Some potential control treatments are suggested below.

486

487 Several positive controls can potentially be used to verify both the efficacy of the FISH protocol 488 and the expected behaviour of all reagents. An example of a positive control to verify basic

489 protocol function is to use a probe against a widely (temporally and in many tissue types)

490 expressed gene such as actin or tubulin with a spatially discrete and predictable staining pattern

491 (Oschwald, Richter \& Grunz, 1991; Kaplan et al., 1992). It can also be informative to target

492 specific genes that are only expressed in known tissue layers or cell types (e.g. neuronal- or

493 epithelial-specific markers). Considering the relative ease and falling cost of generating

494 transcriptome data, it is feasible to also select genes from such data with high levels of

495 expression for use as positive controls in the tissue or developmental stage of interest. Finally, if

496 no signal can be generated in situ with a positive control it may be informative to perform a

497 simple in vitro dot blot. By spotting a diluted series of the probe onto a membrane and detecting

498 these spots with the same reagents used in the in situ experiment any technical problems arising

499 from the reagents can be ruled out or quickly identified.

500

501 Conversely, negative controls can identify nonspecific probe binding for direct labeling and

502 nonspecific antibody binding for indirect labeling experiments. Parallel treatments in which one

503 sample has been pre-treated with RNase will also indicate if the probe is binding exclusively to

504 RNA (no signal is expected in the RNase treated sample). A similar treatment with DNAse will

505 identify any binding to DNA. A sense probe can also be used in parallel with the normal 
506 antisense probe. A sense probe should not form a hybrid within the fixed tissue as it will not be

507 complementary to a target, and thus can only produce non-specific binding. If sense and

508 antisense probes are used in parallel and only the antisense probe produces a signal, and all other

509 controls are also verified, it is likely that the probe is specific and hybridized to the desired

510 mRNA target (Piette et al., 2008). While this combination of controls is commonly employed in

511 the literature and requested by reviewers, it has been reported that some genes are transcribed

512 from both the sense and anti-sense DNA strands (Katayama et al., 2005; Zhang et al., 2006;

513 Hongay et al., 2006; Finocchiaro et al., 2007). A combination of the above controls and

514 experience with a range of probes against different genes will quickly give the user a sense of

515 what is a general non-specific background versus a genuine biological signal.

516

517 Recent advances in FISH protocol development

518 Since the inception of FISH, the core reagents required to perform the technique have remained

519 relatively constant, however, significant advances have been made on the front of probe design

520 and production, as well as signal amplification and detection (Pichon et al., 2018). Recent

521 developments include improvements in the signal strength that can be achieved in small-scale

522 experiments with complex whole-mounts (Choi et al., 2016, 2018; Marras, Bushkin \& Tyagi,

523 2019) as well as the high-throughput protocols that allow for visualization of thousands of

524 transcripts in single cells with quantitative semi-automated data analysis (Moffitt et al., 2016a;

525 Eng et al., 2019).

526

527 Amplification of FISH signal was first achieved through the use of fluorochrome-labeled

528 tyramides that would accumulate at the site of the in situ hybrid due to the use of hapten-labeled 
529 probes and anti-hapten antibodies conjugated to horseradish peroxidase (Raap et al., 1995). This

530 method of tyramide signal amplification (TSA) for FISH is still frequently used to great effect in

531 many sample types including whole-mount invertebrate embryos (Martín-Durán et al., 2016;

532 Schiemann et al., 2017; Gąsiorowski \& Hejnol, 2019) as well as vertebrate embryos and organs

533 (Lauter, Söll \& Hauptmann, 2011; Legendre et al., 2013; Row \& Martin, 2017). A more recent

534 development for FISH signal amplification was introduced by Choi et al. (2010), expanded on by

535 Marras et al. (2019) and is based on the hybridization chain reaction (HCR) introduced by Dirks

536 \& Pierce (2004). In situ HCR uses RNA (Choi et al., 2010, 2014) or DNA (Dirks \& Pierce 2004;

537 Choi et al., 2016, 2018) probes that carry overhang initiator sequences to initiate multiple chain

538 reactions whereby multiple fluorophore-tagged DNA hairpins unfold and assemble into a chain

539 in the vicinity of the probe. This effectively produces multiple strands of fluorophore-laden DNA

540 that are tethered to the probe, thus substantially enhancing the signal. In situ HCR is a non-

541 enzymatic method that boasts shorter protocol lengths ( 36 hours) and does not exhibit the signal

542 diffusion that has been associated with enzyme-based amplification and detection methods.

543

544 Methods for highly multiplexed FISH generally rely on either combinatorial (Lubeck \& Cai,

545 2012; Chen et al., 2015; Moffitt et al., 2016a; Moffitt et al., 2018) or sequential (Lubeck et al.,

546 2014; Shah et al., 2018; Eng et al., 2019) labeling of individual transcripts using probes bearing

547 different fluorophores to create RNA sequence-specific barcodes. Of the modern high-

548 throughput multiplex approaches, multiplexed error robust FISH (MERFISH; Chen et al., 2015)

549 and sequential FISH (seqFISH+; Eng et al., 2019) are two of the most robust options. MERFISH

550 utilizes multiple oligonucleotide probes per target, each probe with a $5^{\prime}$ and $3^{\prime}$ overhang readout

551 sequence that can be separately targeted by a fluorophore-tagged secondary probe. SeqFISH+ 
552 also utilizes multiple singly-labeled oligonucleotide probes per transcript, however, the

553 DNA:RNA hybrids are visualized, destroyed with DNase I, and then replaced using identical

554 probes tagged with a spectrally distinct fluorophore to be imaged again. In both cases, the signals

555 produced by all fluorophores are captured and the patterns are decoded using software to reveal

556 the expression patterns of each gene. With these methods, 10,000 genes can be interrogated

557 simultaneously within a single cell (Eng et al., 2019), or up to 40,000 cells within an 18 hour

558 measurement period (Moffitt et al., 2016a).

559

560 For most FISH protocols that involve labeling one or two target transcripts, qualitative analysis

561 using confocal microscopy is sufficient, however, modern highly multiplexed FISH protocols

562 require computer-assisted image analysis. Currently, single mRNA molecules can be detected

563 using a standard epifluorescence microscope equipped with a charge-coupled device (CCD)

564 camera, although data is typically collected from multiple optical slices using a confocal

565 microscope (Zenklusen \& Singer, 2010; Skinner et al., 2013). For analysis of standard smFISH

566 experiments in cultured cells, it is generally possible to condense the full z-stack to a 2D image

567 as for most genes, abundance is low enough that it is unlikely that two mRNA molecules will

568 occupy the same position in the x-y plane but differ in the z plane (Zenklusen \& Singer, 2010;

569 Trcek et al., 2012). One of the most popular methods to extract data from these images involves

570 fitting a 2D Gaussian mask over each diffraction limited spot to determine the exact signal

571 intensity from each mRNA molecule (Thompson, Larson \& Webb, 2002). Complex high-

572 throughput datasets like those from MERFISH or seqFISH+ require specifically designed

573 algorithms and substantial computational power to decode signals from hundreds of genes across

574 multiple images from a single cell. The details of these analyses are beyond the scope of this 
575 review, but access to the computational pipelines is available through the respective MERFISH

576 (Moffitt et al., 2016a) and seqFISH+ (Eng et al., 2019) publications.

577

578 Since the introduction of RNA-FISH, great progress has been made with respect to the number

579 of targets that can be simultaneously visualized and quantified in situ. Substantial progress has

580 also been made in terms of the complexity of tissues that can be processed, from cultured cells

581 (Singer \& Ward, 1982) to whole embryos (Tautz \& Pfeifle, 1989). Whole mount FISH can be

582 multiplexed to examine several transcripts simultaneously (Meissner et al., 2019) and MERFISH

583 can be performed in tissue sections (Moffitt et al., 2016b). However, whole-mount techniques

584 have not advanced to match what is possible in cultured cells. One requirement to close this gap

585 is further development of imaging technology to visualize single transcripts using highly-

586 multiplexed FISH in whole mounts. Furthermore, the development of signal enhancement

587 methods such as branched DNA ISH (Player et al., 2001; Battich, Stoeger \& Pelkmans, 2015)

588 and HCR (Choi et al., 2010) will likely be a key to acquiring sensitive deep-tissue FISH signals

589 in more complex samples.

590

\section{Conclusions}

592 FISH is a powerful technique that can interrogate the spatial patterns and mechanisms of gene 593 expression in biological systems on scales ranging from the single cell to tissue sections to whole 594 organisms. When coupled with other modern methods that afford broad molecular insight (for 595 example genomics, transcriptomics and gene editing), FISH can increase the precision of genetic 596 information that can be ascertained from unconventional model organisms. However, 597 establishing any kind of ISH method in an understudied system can be extremely time- 
598 consuming. This problem is compounded for the inexperienced user whose first step may be to

599 consult an extremely varied, and at times contradictory, technical literature. In this review, we

600 have attempted to summarise some of the main principles of FISH, and to emphasise those steps

601 that are critical to success. As a starting method, we recommend 4\% PFA or 3.7\% formalin for

602 fixation with $10 \mu \mathrm{g} / \mathrm{mL}$ proteinase $\mathrm{K}$ for permeabilization. The hybridization solution should

603 contain at least formamide (generally 50\%), dextran sulfate, and competitor DNA, but other

604 ingredients and the duration of the hybridization are probe-dependent. Non-specific hybrids can

605 then be removed during the post-hybridization washes using formamide and Tween-20 in SSC at

606 the hybridization temperature, while progressively decreasing salt concentration. Finally, we

607 have also highlighted some of the recent advances in the field and hope that in bringing these

608 points to the attention of the reader, the process of FISH method development and optimisation 609 may be expedited. 


\section{References}

611 Aistleitner K, Jeske R, Wölfel R, Wießner A, Kikhney J, Moter A, Stoecker K. 2018.

612 Detection of Coxiella burnetii in heart valve sections by fluorescence in situ

613 hybridization. Journal of Medical Microbiology 67:537-542. DOI:

$614 \quad 10.1099 / \mathrm{jmm} .0 .000704$.

615 Arrigucci R, Bushkin Y, Radford F, Lakehal K, Vir P, Pine R, Martin D, Sugarman J, Zhao Y, Yap GS, Lardizabal AA, Tyagi S, Gennaro ML. 2017. FISH-Flow, a protocol for the concurrent detection of mRNA and protein in single cells using fluorescence in situ hybridization and flow cytometry. Nature Protocols 12:1245-1260. DOI:

Baker M. 2012. RNA imaging in situ. Nature Methods 9:787-790. DOI: 10.1038/nmeth.2108.

621 Battich N, Stoeger T, Pelkmans L. 2015. Control of transcript variability in single mammalian cells. Cell 163:1596-1610. DOI: 10.1016/j.cell.2015.11.018.

Bauman JG, Wiegant J, Borst P, van Duijn P. 1980. A new method for fluorescence microscopical localization of specific DNA sequences by in situ hybridization of fluorochromelabeled RNA. Experimental Cell Research 128:485-490. synthesis platform for visualizing genomes with Oligopaint FISH probes. Proceedings of the National Academy of Sciences 109:21301-21306. DOI: 10.1073/pnas.1213818110.

Beliveau BJ, Kishi JY, Nir G, Sasaki HM, Saka SK, Nguyen SC, Wu C, Yin P. 2018. OligoMiner provides a rapid, flexible environment for the design of genome-scale 

Sciences 115:E2183-E2192. DOI: 10.1073/pnas.1714530115.

634 Berger SL, Birkenmeier CS. 1979. Inhibition of intractable nucleases with ribonucleoside--

635

636

637

638

639

640

641

642

643

644

645

646

647

648

649

650

651

652

653

654 vanadyl complexes: isolation of messenger ribonucleic acid from resting lymphocytes. Biochemistry 18:5143-5149.

Bienko M, Crosetto N, Teytelman L, Klemm S, Itzkovitz S, Oudenaarden A van. 2013. A versatile genome-scale PCR-based pipeline for high-definition DNA FISH. Nature Methods 10:122-124. DOI: 10.1038/nmeth.2306.

Blake RD, Delcourt SG. 1996. Thermodynamic effects of formamide on DNA stability. Nucleic Acids Research 24:2095-2103.

Bleckmann A, Dresselhaus T. 2016. Fluorescent whole-mount RNA in situ hybridization (FWISH) in plant germ cells and the fertilized ovule. Methods 98:66-73. DOI: 10.1016/j.ymeth.2015.10.019.

Boettiger AN, Levine M. 2013. Rapid transcription fosters coordinate snail expression in the Drosophila embryo. Cell Reports 3:8-15. DOI: 10.1016/j.celrep.2012.12.015.

Bussolati G, Annaratone L, Medico E, D’Armento G, Sapino A. 2011. Formalin fixation at low temperature better preserves nucleic acid integrity. PLOS ONE 6:e21043. DOI: 10.1371/journal.pone.0021043.

Buxbaum AR, Wu B, Singer RH. 2014. Single $\beta$-Actin mRNA detection in neurons reveals a mechanism for regulating its translatability. Science 343:419-422. DOI: 10.1126/science. 1242939 .

Cardinale M, Luvisi A, Meyer JB, Sabella E, De Bellis L, Cruz AC, Ampatzidis Y, Cherubini P. 2018. Specific fluorescence in situ hybridization (FISH) test to highlight 
colonization of xylem vessels by Xylella fastidiosa in naturally infected olive trees (Olea europaea L.). Frontiers in Plant Science 9. DOI: 10.3389/fpls.2018.00431.

657 Carleton J, Lovell PV, McHugh A, Marzulla T, Horback K, Mello CV. 2014. An optimized 658 protocol for high-throughput in situ hybridization of zebra finch brain. Cold Spring Harbor protocols 2014:1249-1258. DOI: 10.1101/pdb.prot084582.

Carr EL, Eales K, Soddell J, Seviour RJ. 2005. Improved permeabilization protocols for 661 fluorescence in situ hybridization (FISH) of mycolic-acid-containing bacteria found in foams. Journal of Microbiological Methods 61:47-54. DOI:

Chen KH, Boettiger AN, Moffitt JR, Wang S, Zhuang X. 2015. Spatially resolved, highly 10.1016/j.mimet.2004.10.023. multiplexed RNA profiling in single cells. Science 348:aaa6090. DOI: situ amplification for multiplexed imaging of mRNA expression. Nature biotechnology 28:1208-1212. DOI: 10.1038/nbt.1692.

Choi HMT, Beck VA, Pierce NA. 2014. Next-generation in situ hybridization chain reaction: Higher gain, lower cost, greater durability. ACS Nano 8:4284-4294. DOI: Lee SM, Abelin ACT, Rosenthal AZ, Akbari OS, Li Y, Hay BA, Sternberg PW, Patterson PH, Davidson EH, Mazmanian SK, Prober DA, Rijn M van de, Leadbetter JR, Newman DK, Readhead C, Bronner ME, Wold B, Lansford R, 
677

678

679

680

681

682

683

684

685

686

687

688

689

690

691

692

693

694

695

696

697

698

699

Sauka-Spengler T, Fraser SE, Pierce NA. 2016. Mapping a multiplexed zoo of mRNA expression. Development 143:3632-3637. DOI: 10.1242/dev.140137.

Choi HMT, Schwarzkopf M, Fornace ME, Acharya A, Artavanis G, Stegmaier J, Cunha A, Pierce NA. 2018. Third-generation in situ hybridization chain reaction: multiplexed, quantitative, sensitive, versatile, robust. Development 145. DOI: 10.1242/dev.165753.

Choo KHA. 2008. In Situ Hybridization Protocols. Springer Science \& Business Media.

Croll RP, Voronezhskaya EE, Hiripi L, Elekes K. 1999. Development of catecholaminergic neurons in the pond snail, Lymnaea stagnalis: II. Postembryonic development of central and peripheral cells. The Journal of Comparative Neurology 404:297-309.

Donà F, Houseley J. 2014. Unexpected DNA loss mediated by the DNA binding activity of ribonuclease A. PLoS ONE 9. DOI: 10.1371/journal.pone.0115008.

Eliscovich C, Shenoy SM, Singer RH. 2017. Imaging mRNA and protein interactions within neurons. Proceedings of the National Academy of Sciences 114:E1875-E1884. DOI: $10.1073 /$ pnas. 1621440114

Eltoum I, Fredenburgh J, Myers RB, Grizzle WE. 2001. Introduction to the theory and practice of fixation of tissues. Journal of Histotechnology 24:173-190. DOI: 10.1179/his.2001.24.3.173.

Eng C-HL, Lawson M, Zhu Q, Dries R, Koulena N, Takei Y, Yun J, Cronin C, Karp C, Yuan G-C, Cai L. 2019. Transcriptome-scale super-resolved imaging in tissues by RNA seqFISH. Nature 568:235-239. DOI: 10.1038/s41586-019-1049-y.

Felsenfeld G, Miles H. 1967. The physical and chemical properties of nucleic acids. Annual Review of Biochemistry 36:407-448. DOI: 10.1146/annurev.bi.36.070167.002203. 
700 Femino AM, Fay FS, Fogarty K, Singer RH. 1998. Visualization of single RNA transcripts in

701

702

703

704

705

706

707

708

709

710

711

712

713

714

715

716

717

718

719

720

721

722 situ. Science 280:585-590. DOI: 10.1126/science.280.5363.585.

Finnerty JR, Paulson D, Burton P, Pang K, Martindale MQ. 2003. Early evolution of a homeobox gene: the parahox gene Gsx in the Cnidaria and the Bilateria. Evolution \& Development 5:331-345. DOI: 10.1046/j.1525-142X.2003.03041.x.

Finocchiaro G, Carro MS, Francois S, Parise P, DiNinni V, Muller H. 2007. Localizing hotspots of antisense transcription. Nucleic Acids Research 35:1488-1500. DOI: 10.1093/nar/gkm027.

Fontenete S, Guimarães N, Wengel J, Azevedo NF. 2016. Prediction of melting temperatures in fluorescence in situ hybridization (FISH) procedures using thermodynamic models. Critical Reviews in Biotechnology 36:566-577. DOI: 10.3109/07388551.2014.993589.

Fowler CB, Evers DL, O’Leary TJ, Mason JT. 2011. Antigen retrieval causes protein unfolding. Journal of Histochemistry and Cytochemistry 59:366-381. DOI: $10.1369 / 0022155411400866$.

Fox CH, Johnson FB, Whiting J, Roller PP. 1985. Formaldehyde fixation. Journal of Histochemistry \& Cytochemistry 33:845-853. DOI: 10.1177/33.8.3894502.

Franks AH, Harmsen HJM, Raangs GC, Jansen GJ, Schut F, Welling GW. 1998. Variations of bacterial populations in human feces measured by fluorescent in situ hybridization with group-specific 16S rRNA-targeted oligonucleotide probes. Applied and Environmental Microbiology 64:3336-3345.

Frazier AD, Champney WS. 2012. The vanadyl ribonucleoside complex inhibits ribosomal subunit formation in Staphylococcus aureus. Journal of Antimicrobial Chemotherapy 67:2152-2157. DOI: $10.1093 / \mathrm{jac} / \mathrm{dks} 182$. 
723 Gall JG, Pardue ML. 1969. Formation and detection of RNA-DNA hybrid molecules in

724

725

726

727

728

729

730

731

732

733

734

735

736

737

738

739

740

741

742

743

744

cytological preparations. Proceedings of the National Academy of Sciences of the United States of America 63:378-383.

Gąsiorowski L, Hejnol A. 2019. Hox gene expression in postmetamorphic juveniles of the brachiopod Terebratalia transversa. EvoDevo 10. DOI: 10.1186/s13227-018-0114-1.

van Gijlswijk RP, Wiegant J, Raap AK, Tanke HJ. 1996. Improved localization of

fluorescent tyramides for fluorescence in situ hybridization using dextran sulfate and polyvinyl alcohol. Journal of Histochemistry \& Cytochemistry 44:389-392. DOI:

10.1177/44.4.8601698.

Hauptmann G, Söll I, Krautz R, Theopold U. 2016. Multi-target chromogenic whole-mount in situ hybridization for comparing gene expression domains in Drosophila embryos. Journal of Visualized Experiments : JoVE. DOI: 10.3791/53830.

Hejnol A, Martindale MQ. 2008. Acoel development indicates the independent evolution of the bilaterian mouth and anus. Nature 456:382-386. DOI: 10.1038/nature07309.

Hicks DG, Tubbs RR. 2005. Assessment of the HER2 status in breast cancer by fluorescence in situ hybridization: a technical review with interpretive guidelines. Human Pathology 36:250-261. DOI: 10.1016/j.humpath.2004.11.010.

\section{Hoetelmans RW, Prins FA, Cornelese-ten Velde I, van der Meer J, van de Velde CJ, van} Dierendonck JH. 2001. Effects of acetone, methanol, or paraformaldehyde on cellular structure, visualized by reflection contrast microscopy and transmission and scanning electron microscopy. Applied immunohistochemistry \& molecular morphology: AIMM 9:346-351. 
745 Hongay CF, Grisafi PL, Galitski T, Fink GR. 2006. Antisense transcription controls cell fate 746 in Saccharomyces cerevisiae. Cell 127:735-745. DOI: 10.1016/j.cell.2006.09.038.

747

748

749

750

751

752

753

754

755

756

757

758

759

760

761

762

763

764

765

766

767

Hougaard DM, Hansen H, Larsson L-I. 1997. Non-radioactive in situ hybridization for mRNA with emphasis on the use of oligodeoxynucleotide probes. Histochemistry and Cell Biology 108:335-344. DOI: 10.1007/s004180050174.

Hua R, Yu S, Liu M, Li H. 2018. A PCR-based method for RNA probes and applications in neuroscience. Frontiers in Neuroscience 12. DOI: 10.3389/fnins.2018.00266.

Insam H, Franke-Whittle I, Goberna M. 2009. Microbes at work: From wastes to resources. Springer Science \& Business Media.

Jackson DJ, Herlitze I, Hohagen J. 2016. A whole mount in situ hybridization method for the gastropod mollusc Lymnaea stagnalis. Journal of Visualized Experiments. DOI: $10.3791 / 53968$.

Jandura A, Hu J, Wilk R, Krause HM. 2017. High resolution fluorescent in situ hybridization in Drosophila embryos and tissues using tyramide signal amplification. Journal of Visualized Experiments : JoVE. DOI: 10.3791/56281.

Jékely G, Arendt D. 2007. Cellular resolution expression profiling using confocal detection of NBT/BCIP precipitate by reflection microscopy. BioTechniques 42:751-755. DOI: $10.2144 / 000112462$

Kaplan BB, Gioio AE, Capano CP, Crispino M, Giuditta A. 1992. beta-actin and beta-tubulin are components of a heterogeneous mRNA population present in the squid giant axon. Molecular and Cellular Neurosciences 3:133-144.

Kasai A, Kakihara S, Miura H, Okada R, Hayata-Takano A, Hazama K, Niu M, Shintani N, Nakazawa T, Hashimoto H. 2016. Double in situ hybridization for microRNAs and 
mRNAs in brain tissues. Frontiers in Molecular Neuroscience 9. DOI:

10.3389/fnmol.2016.00126.

770

771

772

773

774

775

776

777

778

779

780

781

782

783

784

785

786

787

788

789

Katayama S, Tomaru Y, Kasukawa T, Waki K, Nakanishi M, Nakamura M, Nishida H, Yap CC, Suzuki M, Kawai J, Suzuki H, Carninci P, Hayashizaki Y, Wells C, Frith M, Ravasi T, Pang KC, Hallinan J, Mattick J, Hume DA, Lipovich L, Batalov S, Engström PG, Mizuno Y, Faghihi MA, Sandelin A, Chalk AM, Mottagui-Tabar S, Liang Z, Lenhard B, Wahlestedt C, RIKEN Genome Exploration Research Group, Genome Science Group (Genome Network Project Core Group), FANTOM Consortium. 2005. Antisense transcription in the mammalian transcriptome. Science (New York, N.Y.) 309:1564-1566. DOI: 10.1126/science.1112009.

Keller W, Crouch R. 1972. Degradation of DNA RNA hybrids by ribonuclease H and DNA polymerases of cellular and viral origin. Proceedings of the National Academy of Sciences of the United States of America 69:3360-3364.

Kempf VAJ, Trebesius K, Autenrieth IB. 2000. Fluorescent in situ hybridization allows rapid identification of microorganisms in blood cultures. Journal of Clinical Microbiology 38:830-838.

Kernohan KD, Bérubé NG. 2014. Three dimensional dual labeled DNA fluorescent in situ hybridization analysis in fixed tissue sections. Methods X 1:30-35. DOI: 10.1016/j.mex.2014.04.001.

Kislauskis EH, Li Z, Singer RH, Taneja KL. 1993. Isoform-specific 3'-untranslated sequences sort alpha-cardiac and beta-cytoplasmic actin messenger RNAs to different cytoplasmic compartments. The Journal of Cell Biology 123:165-172. 
790 Kucho K, Yoneda H, Harada M, Ishiura M. 2004. Determinants of sensitivity and specificity

791

792

793

794

795

796

797

798

799

800

801

802

803

804

805

806

807

808

809

810

811 in spotted DNA microarrays with unmodified oligonucleotides. Genes \& Genetic Systems 79:189-197. DOI: 10.1266/ggs.79.189.

Kuwajima T, Sitko AA, Bhansali P, Jurgens C, Guido W, Mason C. 2013. ClearT: a detergent- and solvent-free clearing method for neuronal and non-neuronal tissue. Development 140:1364-1368. DOI: 10.1242/dev.091844.

Lanfranco MF, Loane D, Mocchetti I, Burns M, Villapol S. 2017. Combination of fluorescent in situ hybridization (FISH) and immunofluorescence imaging for detection of cytokine expression in microglia/macrophage cells. BIO-PROTOCOL 7. DOI: 10.21769/BioProtoc. 2608 .

Langenbacher AD, Rodriguez D, Di Maio A, De Tomaso AW. 2015. Whole-mount fluorescent in situ hybridization staining of the colonial tunicate Botryllus schlosseri. Genesis (New York, N.Y.: 2000) 53:194-201. DOI: 10.1002/dvg.22820.

Lauter G, Söll I, Hauptmann G. 2011a. Multicolor fluorescent in situ hybridization to define abutting and overlapping gene expression in the embryonic zebrafish brain. Neural Development 6:10. DOI: 10.1186/1749-8104-6-10.

Lauter G, Söll I, Hauptmann G. 2011b. Two-color fluorescent in situ hybridization in the embryonic zebrafish brain using differential detection systems. BMC Developmental Biology 11:43. DOI: 10.1186/1471-213X-11-43.

Lederman L, Kawasaki ES, Szabo P. 1981. The rate of nucleic acid annealing to cytological preparations is increased in the presence of dextran sulfate. Analytical Biochemistry 117:158-163. DOI: 10.1016/0003-2697(81)90705-3. 
812 Legendre F, Cody N, Iampietro C, Bergalet J, Lefebvre FA, Moquin-Beaudry G, Zhang O,

813 Wang X, Lécuyer E. 2013. Whole mount RNA fluorescent in situ hybridization of

814 Drosophila embryos. Journal of Visualized Experiments: JoVE. DOI: 10.3791/50057.

815 Levitt D, King M. 1987. Methanol fixation permits flow cytometric analysis of

816 immunofluorescent stained intracellular antigens. Journal of Immunological Methods

817 96:233-237. DOI: 10.1016/0022-1759(87)90319-X.

818 Levsky JM, Shenoy SM, Pezo RC, Singer RH. 2002. Single-cell gene expression profiling.

$819 \quad$ Science 297:836-840.

820 Little SC, Gregor T. 2018. Single mRNA molecule detection in Drosophila. Methods in

821 molecular biology (Clifton, N.J.) 1649:127-142. DOI: 10.1007/978-1-4939-7213-5_8.

822 Liu W, Zhang H, Xiang Y, Jia K, Luo M, Yi M. 2019. Molecular characterization of vasa homologue in marbled goby, Oxyeleotris marmorata: Transcription and localization

824

825 analysis during gametogenesis and embryogenesis. Comparative Biochemistry and Physiology Part B: Biochemistry and Molecular Biology 229:42-50. DOI:

826 10.1016/j.cbpb.2018.12.005.

827 Lubeck E, Cai L. 2012. Single cell systems biology by super-resolution imaging and 828 combinatorial labeling. Nature methods 9:743-748. DOI: 10.1038/nmeth.2069.

829 Lubeck E, Coskun AF, Zhiyentayev T, Ahmad M, Cai L. 2014. Single cell in situ RNA 830 profiling by sequential hybridization. Nature methods 11:360-361. DOI:

831 10.1038/nmeth.2892.

832

Lyubimova A, Itzkovitz S, Junker JP, Fan ZP, Wu X, van Oudenaarden A. 2013. Single-

833 molecule mRNA detection and counting in mammalian tissue. Nature Protocols 8:1743-

834 1758. DOI: $10.1038 /$ nprot.2013.109. 
835 Macnaughton SJ, O’Donnell AG, Embley TM. 1994. Permeabilization of mycolic-acid-

836 containing actinomycetes for in situ hybridization with fluorescently labeled

837

838 oligonucleotide probes. Microbiology 140:2859-2865. DOI: 10.1099/00221287-140-102859.

Manz W, Wagner M, Amann R, Schleifer K-H. 1994. In situ characterization of the microbial consortia active in two wastewater treatment plants. Water Research 28:1715-1723.

Marra AN, Ulrich M, White A, Springer M, Wingert RA. 2017. Visualizing multiciliated cells in the zebrafish through a combined protocol of whole mount fluorescent in situ hybridization and immunofluorescence. Journal of Visualized Experiments : JoVE. DOI: $10.3791 / 56261$

845

846

847

848

849

850

851

852

853

854

855

856

857

Marras SAE, Bushkin Y, Tyagi S. 2019. High-fidelity amplified FISH for the detection and allelic discrimination of single mRNA molecules. Proceedings of the National Academy of Sciences 116:13921-13926. DOI: 10.1073/pnas.1814463116.

Martindale MQ, Pang K, Finnerty JR. 2004. Investigating the origins of triploblasty: 'mesodermal' gene expression in a diploblastic animal, the sea anemone Nematostella vectensis (phylum, Cnidaria; class, Anthozoa). Development 131:2463-2474. DOI: 10.1242/dev.01119.

McConaughy BL, Laird CD, McCarthy BJ. 1969. Nucleic acid reassociation in formamide. Biochemistry 8:3289-3295. DOI: 10.1021/bi00836a024.

\section{Meissner GW, Nern A, Singer RH, Wong AM, Malkesman O, Long X. 2019. Mapping} neurotransmitter identity in the whole-mount drosophila brain using multiplex highthroughput fluorescence in situ hybridization. Genetics 211:473-482. DOI: 10.1534/genetics.118.301749. 
858 Meyer C, Garzia A, Tuschl T. 2017. Simultaneous detection of the subcellular localization of

859

860

861

862

863

864

865

866

867

868

869

870

871

872

873

874

875

876

877

878

879

RNAs and proteins in cultured cells by combined multicolor RNA-FISH and IF. Methods (San Diego, Calif.) 118-119:101-110. DOI: 10.1016/j.ymeth.2016.09.010.

Milman G, Langridge R, Chamberlin MJ. 1967. The structure of a DNA-RNA hybrid. Proceedings of the National Academy of Sciences 57:1804-1810. DOI: 10.1073/pnas.57.6.1804.

Moffitt JR, Hao J, Wang G, Chen KH, Babcock HP, Zhuang X. 2016a. High-throughput single-cell gene-expression profiling with multiplexed error-robust fluorescence in situ hybridization. Proceedings of the National Academy of Sciences 113:11046-11051. DOI: 10.1073/pnas.1612826113.

Moffitt JR, Hao J, Bambah-Mukku D, Lu T, Dulac C, Zhuang X. 2016b. High-performance multiplexed fluorescence in situ hybridization in culture and tissue with matrix imprinting and clearing. Proceedings of the National Academy of Sciences 113:1445614461. DOI: $10.1073 /$ pnas.1617699113.

Moffitt JR, Bambah-Mukku D, Eichhorn SW, Vaughn E, Shekhar K, Perez JD, Rubinstein ND, Hao J, Regev A, Dulac C, Zhuang X. 2018. Molecular, spatial and functional single-cell profiling of the hypothalamic preoptic region. Science 362. DOI: 10.1126/science.aau5324.

Moorman AFM, Houweling AC, de Boer PAJ, Christoffels VM. 2001. Sensitive nonradioactive detection of mRNA in tissue sections: Novel application of the wholemount in situ hybridization protocol. Journal of Histochemistry \& Cytochemistry 49:1-8. DOI: $10.1177 / 002215540104900101$. 
880 Nagaso H, Murata T, Day N, Yokoyama KK. 2001. Simultaneous detection of RNA and

881

882

883

884

885

886

887

888

889

890

891

892

893

894

895

896

897

898

899

900

901

protein by in situ hybridization and immunological staining. The Journal of

Histochemistry and Cytochemistry 49:1177-1182. DOI: 10.1177/002215540104900911.

Nakamura T, Nakamura T, Hamada H. 2013. Fluorescent 2 color whole mount in situ hybridization for a mouse embryo. Protocol Exchange. DOI: 10.1038/protex.2013.002.

Neufeld SJ, Zhou X, Vize PD, Cobb J. 2013. mRNA fluorescence in situ hybridization to determine overlapping gene expression in whole-mount mouse embryos. Developmental Dynamics 242:1094-1100. DOI: 10.1002/dvdy.23993.

Oka Y, Sato TN. 2015. Whole-mount single molecule FISH method for zebrafish embryo. Scientific Reports 5. DOI: 10.1038/srep08571.

Oliveira VC, Carrara RCV, Simoes DLC, Saggioro FP, Carlotti CG, Covas DT, Neder L. 2010. Sudan Black B treatment reduces autofluorescence and improves resolution of in situ hybridization specific fluorescent signals of brain sections. Histology and Histopathology 25:1017-1024. DOI: 10.14670/HH-25.1017.

Oschwald R, Richter K, Grunz H. 1991. Localization of a nervous system-specific class II beta-tubulin gene in Xenopus laevis embryos by whole-mount in situ hybridization. The International Journal of Developmental Biology 35:399-405.

Oxtoby E, Jowett T. 1993. Cloning of the zebrafish krox-20 gene (krx-20) and its expression during hindbrain development. Nucleic Acids Research 21:1087-1095.

Pardue ML, Gall JG. 1969. Molecular hybridization of radioactive DNA to the DNA of cytological preparations. Proceedings of the National Academy of Sciences of the United States of America 64:600-604.

Peer) reviewing PDF | (2019:08:40312:1:0:NEW 11 Feb 2020) 
902 Paré A, Lemons D, Kosman D, Beaver W, Freund Y, McGinnis W. 2009. Transcriptional

903 analysis of the Hox gene Scr at single molecule resolution yields evidence for

904 transcriptional bursting during Drosophila embryogenesis. Current Biology. 19:2037-

905 2042. DOI: $\underline{10.1016 / \text { j.cub.2009.10.028. }}$.

906 Parker LM, Sayyadi N, Staikopoulos V, Shrestha A, Hutchinson MR, Packer NH. 2019.

907 Visualizing neuroinflammation with fluorescence and luminescent lanthanide-based in

908 situ hybridization. Journal of Neuroinflammation 16:65. DOI: 10.1186/s12974-019-1451-

9092.

910 Pearson BJ, Eisenhoffer GT, Gurley KA, Rink JC, Miller DE, Sánchez Alvarado A. 2009.

911 Formaldehyde-based whole-mount in situ hybridization method for planarians.

912 Developmental Dynamics 238:443-450. DOI: 10.1002/dvdy.21849.

913 Pichon X, Lagha M, Mueller F, Bertrand E. 2018. A growing toolbox to image gene

914 expression in single cells: Sensitive approaches for demanding challenges. Molecular

915 Cell 71:468-480. DOI: 10.1016/j.molcel.2018.07.022.

916 Piette D, Hendrickx M, Willems E, Kemp CR, Leyns L. 2008. An optimized procedure for

917 whole-mount in situ hybridization on mouse embryos and embryoid bodies. Nature

918 Protocols 3:1194-1201. DOI: 10.1038/nprot.2008.103.

919 Pinkel D, Landegent J, Collins C, Fuscoe J, Segraves R, Lucas J, Gray J. 1988. Fluorescence

920 in situ hybridization with human chromosome-specific libraries: detection of trisomy 21

921

922 and translocations of chromosome 4. Proceedings of the National Academy of Sciences 85:9138-9142. 
923 Player AN, Shen L-P, Kenny D, Antao VP, Kolberg JA. 2001. Single-copy gene detection

924 using branched DNA (bDNA) in situ hybridization. Journal of Histochemistry \&

925 Cytochemistry 49:603-611. DOI: 10.1177/002215540104900507.

926 Qi L, Knapton EK, Zhang X, Zhang T, Gu C, Zhao Y. 2017. Pre-culture sudan black B

927 treatment suppresses autofluorescence signals emitted from polymer tissue scaffolds.

928 Scientific Reports 7:8361. DOI: 10.1038/s41598-017-08723-2.

929

930

931

932

933

934

935

936

937

938

939

940

941

942

943

944

945

Raap AK, van de Corput MPC, Vervenne R a. M, van Gijlswijk RPM, Tanke HJ, Wiegant J. 1995. Ultra-sensitive FISH using peroxidase-mediated deposition of biotin- or fluorochrome tyramides. Human Molecular Genetics 4:529-534. DOI: 10.1093/hmg/4.4.529.

Raj A, Peskin CS, Tranchina D, Vargas DY, Tyagi S. 2006. Stochastic mRNA Synthesis in Mammalian Cells. PLOS Biology 4:e309. DOI: 10.1371/journal.pbio.0040309.

Raj A, van den Bogaard P, Rifkin SA, van Oudenaarden A, Tyagi S. 2008. Imaging individual mRNA molecules using multiple singly labeled probes. Nature methods 5:877-879. DOI: 10.1038/nmeth.1253.

Raj A, van Oudenaarden A. 2009. Single-molecule approaches to stochastic gene expression. Annual Review of Biophysics 38:255-270. DOI: 10.1146/annurev.biophys.37.032807.125928.

Randolph JB, Waggoner AS. 1997. Stability, specificity and fluorescence brightness of multiply-labeled fluorescent DNA probes. Nucleic Acids Research 25:2923-2929. DOI: 10.1093/nar/25.14.2923.

Rich A. 1959. An analysis of the relation between DNA and RNA. Annals of the New York Academy of Sciences 81:709-722. DOI: 10.1111/j.1749-6632.1959.tb49352.x. 
946 Rich A. 1960. A hybrid helix containing both deoxyribose and ribose polynucleotides and its

947

948

949

950

951

952

953

954

955

956

957

958

959

960

961

962

963

964

965

966

967 relation to the transfer of information between the nucleic acids. Proceedings of the National Academy of Sciences of the United States of America 46:1044-1053.

Richardson DS, Lichtman JW. 2015. Clarifying tissue clearing. Cell 162:246-257. DOI: 10.1016/j.cell.2015.06.067.

Rink JC, Vu HT-K, Alvarado AS. 2011. The maintenance and regeneration of the planarian excretory system are regulated by EGFR signaling. Development 138:3769-3780. DOI: 10.1242/dev.066852.

Rocha R, Almeida C, Azevedo NF. 2018. Influence of the fixation/permeabilization step on peptide nucleic acid fluorescence in situ hybridization (PNA-FISH) for the detection of bacteria. PLOS ONE 13:e0196522. DOI: 10.1371/journal.pone.0196522.

Row RH, Martin BL. 2017. itFISH: Enhanced staining by iterative fluorescent in situ hybridization. Zebrafish 14:578-580. DOI: 10.1089/zeb.2016.1413.

Rudkin GT, Stollar BD. 1977. High resolution detection of DNA-RNA hybrids in situ by indirect immunofluorescence. Nature 265:472-473. DOI: 10.1038/265472a0.

Schiemann SM, Martín-Durán JM, Børve A, Vellutini BC, Passamaneck YJ, Hejnol A. 2017. Clustered brachiopod Hox genes are not expressed collinearly and are associated with lophotrochozoan novelties. Proceedings of the National Academy of Sciences of the United States of America 114:E1913-E1922. DOI: 10.1073/pnas.1614501114.

Schurter MJ, LeBrun DP, Harrison KJ. 2002. Improved technique for fluorescence in situ hybridisation analysis of isolated nuclei from archival, B5 or formalin fixed, paraffin wax embedded tissue. Molecular Pathology 55:121-124. 
968 Sepsi A, Fábián A, Jäger K, Heslop-Harrison JS, Schwarzacher T. 2018. ImmunoFISH:

969 Simultaneous visualisation of proteins and DNA sequences gives insight into meiotic

$970 \quad$ processes in nuclei of grasses. Frontiers in Plant Science 9. DOI:

$971 \quad 10.3389 /$ fpls.2018.01193.

972 Shaffer SM, Wu M-T, Levesque MJ, Raj A. 2013. Turbo FISH: A method for rapid single 973 molecule RNA FISH. PLoS ONE 8. DOI: 10.1371/journal.pone.0075120.

974 Shah S, Takei Y, Zhou W, Lubeck E, Yun J, Eng C-HL, Koulena N, Cronin C, Karp C,

975 Liaw EJ, Amin M, Cai L. 2018. Dynamics and spatial genomics of the nascent

976 transcriptome by intron seqFISH. Cell 174:363-376.e16. DOI:

$977 \quad$ 10.1016/j.cell.2018.05.035.

978 Shiura H, Okamoto A, Sasaki H, Abe K. 2014. Whole-mount MeFISH: A novel technique for 979 simultaneous visualization of specific DNA methylation and protein/RNA expression.

980 PLOS ONE 9:e95750. DOI: 10.1371/journal.pone.0095750.

981

Singer RH, Ward DC. 1982. Actin gene expression visualized in chicken muscle tissue culture

982

983 by using in situ hybridization with a biotinated nucleotide analog. Proceedings of the National Academy of Sciences of the United States of America 79:7331-7335.

Singh L, Jones KW. 1984. The use of heparin as a simple cost-effective means of controlling background in nucleic acid hybridization procedures. Nucleic Acids Research 12:56275638.

Sinigaglia C, Thiel D, Hejnol A, Houliston E, Leclère L. 2018. A safer, urea-based in situ

988 hybridization method improves detection of gene expression in diverse animal species. Developmental Biology 434:15-23. DOI: 10.1016/j.ydbio.2017.11.015. 
990 Skinner SO, Sepúlveda LA, Xu H, Golding I. 2013. Measuring mRNA copy-number in

991 individual Escherichia coli cells using single-molecule fluorescent in situ hybridization

992 (smFISH). Nature protocols 8:1100-1113. DOI: 10.1038/nprot.2013.066.

993 Steinmetz PRH, Kostyuchenko RP, Fischer A, Arendt D. 2011. The segmental pattern of otx, 994 gbx, and Hox genes in the annelid Platynereis dumerilii. Evolution \& Development 995 996

997

998 13:72-79. DOI: 10.1111/j.1525-142X.2010.00457.x.

Susaki EA, Tainaka K, Perrin D, Yukinaga H, Kuno A, Ueda HR. 2015. Advanced CUBIC protocols for whole-brain and whole-body clearing and imaging. Nature Protocols 10:1709-1727. DOI: 10.1038/nprot.2015.085.

Szabo Q, Jost D, Chang J-M, Cattoni DI, Papadopoulos GL, Bonev B, Sexton T, Gurgo J, 1000 Jacquier C, Nollmann M, Bantignies F, Cavalli G. 2018. TADs are 3D structural units

1001

1002

1003

1004

1005 of higher-order chromosome organization in Drosophila. Science Advances 4:eaar8082.

1006 DOI: $10.1126 /$ sciadv.aar8082.

Tainaka K, Kubota SI, Suyama TQ, Susaki EA, Perrin D, Ukai-Tadenuma M, Ukai H, Ueda HR. 2014. Whole-body imaging with single-cell resolution by tissue decolorization. Cell 159:911-924. DOI: 10.1016/j.cell.2014.10.034.

Taniguchi Y, Choi PJ, Li G-W, Chen H, Babu M, Hearn J, Emili A, Xie XS. 2010. Quantifying E. coli proteome and transcriptome with single-molecule sensitivity in single cells. Science (New York, N.Y.) 329:533-538. DOI: 10.1126/science.1188308.

1010 Tanner M, Gancberg D, Di Leo A, Larsimont D, Rouas G, Piccart MJ, Isola J. 2000.

1011 Chromogenic in situ hybridization. The American Journal of Pathology 157:1467-1472. 
1012 Tautz D, Pfeifle C. 1989. A non-radioactive in situ hybridization method for the localization of

1013

1014

1015

1016

1017

1018

1019

1020

1021

1022

1023

1024

1025

1026

1027

1028

1029

1030

1031

1032

1033 specific RNAs in Drosophila embryos reveals translational control of the segmentation gene hunchback. Chromosoma 98:81-85. DOI: 10.1007/bf00291041.

Teng X, Zhang S, Liu W, Bi K, Zhang L. 2017. A new method for real-time evaluation of pepsin digestion of paraffin-embedded tissue sections, prior to fluorescence in situ hybridisation. Virchows Archiv: An International Journal of Pathology 470:567-573. DOI: $10.1007 / \mathrm{s} 00428-017-2097-\mathrm{z}$.

Tessmar-Raible K, Steinmetz PRH, Snyman H, Hassel M, Arendt D. 2005. Fluorescent twocolor whole mount in situ hybridization in Platynereis dumerilii (Polychaeta, Annelida), an emerging marine molecular model for evolution and development. BioTechniques 39:460-464. DOI: 10.2144/000112023.

Thavarajah R, Mudimbaimannar VK, Elizabeth J, Rao UK, Ranganathan K. 2012. Chemical and physical basics of routine formaldehyde fixation. Journal of Oral and Maxillofacial Pathology: JOMFP 16:400-405. DOI: 10.4103/0973-029X.102496.

Thiruketheeswaran P, Kiehl E, D'Haese J. 2016. Soluble calcium-binding proteins (SCBPs) of the earthworm Lumbricus terrestris: molecular characterization and localization by FISH in muscle and neuronal tissue. Histochemistry and Cell Biology 146:635-644. DOI: 10.1007/s00418-016-1463-2.

Thompson RE, Larson DR, Webb WW. 2002. Precise nanometer localization analysis for individual fluorescent probes. Biophysical Journal 82:2775-2783.

Titford M. 2001. Safety considerations in the use of fixatives. Journal of Histotechnology 24:165-171. DOI: 10.1179/his.2001.24.3.165. 
1034 Trcek T, Chao JA, Larson DR, Park HY, Zenklusen D, Shenoy SM, Singer RH. 2012.

1035 Single-mRNA counting using fluorescent in situ hybridization in budding yeast. Nature

1036 protocols 7:408-419. DOI: 10.1038/nprot.2011.451.

1037 Trcek T, Lionnet T, Shroff H, Lehmann R. 2017. mRNA quantification using single-molecule 1038 FISH in Drosophila embryos. Nature protocols 12:1326-1348. DOI:

1039 10.1038/nprot.2017.030.

1040

Volpi EV. 2017. Formamide-free fluorescence in situ hybridization (FISH). In: Liehr T ed.

1041

1042

1043

1044

1045

1046

1047

1048

1049

1050

1051

1052

1053

1054

1055

1056

Fluorescence in situ hybridization (FISH). Springer Protocols Handbooks. Springer Berlin Heidelberg, 135-139. DOI: 10.1007/978-3-662-52959-1_12.

Volpi EV, Bridger JM. 2008. FISH glossary: an overview of the fluorescence in situ hybridization technique. BioTechniques 45:385-390. DOI: 10.2144/000112811.

Wang W, Tang Y, Li J, Jiang L, Jiang Y, Su X. 2015. Detection of ALK rearrangements in malignant pleural effusion cell blocks from patients with advanced non-small cell lung cancer: A comparison of Ventana immunohistochemistry and fluorescence in situ hybridization. Cancer Cytopathology 123:117-122. DOI: 10.1002/cncy.21510.

Warheit DB, Kinney LA, Carakostas MC, Ross PE. 1989. Inhalation toxicity study of formamide in rats. Toxicological Sciences 13:702-713. DOI: 10.1093/toxsci/13.4.702.

Wiegant J, Bezrookove V, Rosenberg C, Tanke HJ, Raap AK, Zhang H, Bittner M, Trent JM, Meltzer P. 2000. Differentially painting human chromosome arms with combined binary ratio-labeling fluorescence in situ hybridization. Genome Research 10:861-865.

Wyeth RC, Croll RP. 2011. Peripheral sensory cells in the cephalic sensory organs of Lymnaea stagnalis. The Journal of Comparative Neurology 519:1894-1913. DOI: 10.1002/cne. 22607 . 
1057 Yoon DS, Pendergrass DL, Lee M-H. 2016. A simple and rapid method for combining 1058 fluorescent in situ RNA hybridization (FISH) and immunofluorescence in the C. elegans 1059 germline. Methods X 3:378-385. DOI: 10.1016/j.mex.2016.05.001.

1060 Zenklusen D, Singer RH. 2010. Analyzing mRNA Expression using single mRNA resolution 1061 fluorescent in situ hybridization. Methods in enzymology 470:641-659. DOI:

$1062 \quad 10.1016 / \mathrm{S} 0076-6879(10) 70026-4$.

1063 Zhang Y, Liu XS, Liu Q-R, Wei L. 2006. Genome-wide in silico identification and analysis of 1064 cis natural antisense transcripts (cis-NATs) in ten species. Nucleic Acids Research 1065 34:3465-3475. DOI: 10.1093/nar/gkl473.

1066 Zhang J, Lang HP, Yoshikawa G, Gerber C. 2012. Optimization of DNA hybridization 1067 efficiency by pH-driven nanomechanical bending. Langmuir 28:6494-6501. DOI: 1068 10.1021/la205066h.

1069 


\section{Figure 1}

Schematic representation of the technical development of fluorescent in situ hybridization (FISH).

In situ hybridization (ISH) was first performed by Gall and Parude in 1969 using radioactive probes. Fluorescent ISH (FISH) against DNA was first performed by Rudkin and Stollar in 1977. FISH against RNA (RNA-FISH) was first performed by Singer and Ward in 1982. RNAFISH that could be used to resolve individual mRNA transcripts was first performed by Femino et al. in 1998 and later improved upon in whole mount tissue by Raj et al. in 2008. Horseradish peroxidase-based chromogenic (or colorimetric) ISH was later introduced by Tanner et al. in 2000 as an alternative FISH without the need for a fluorescence microscope.

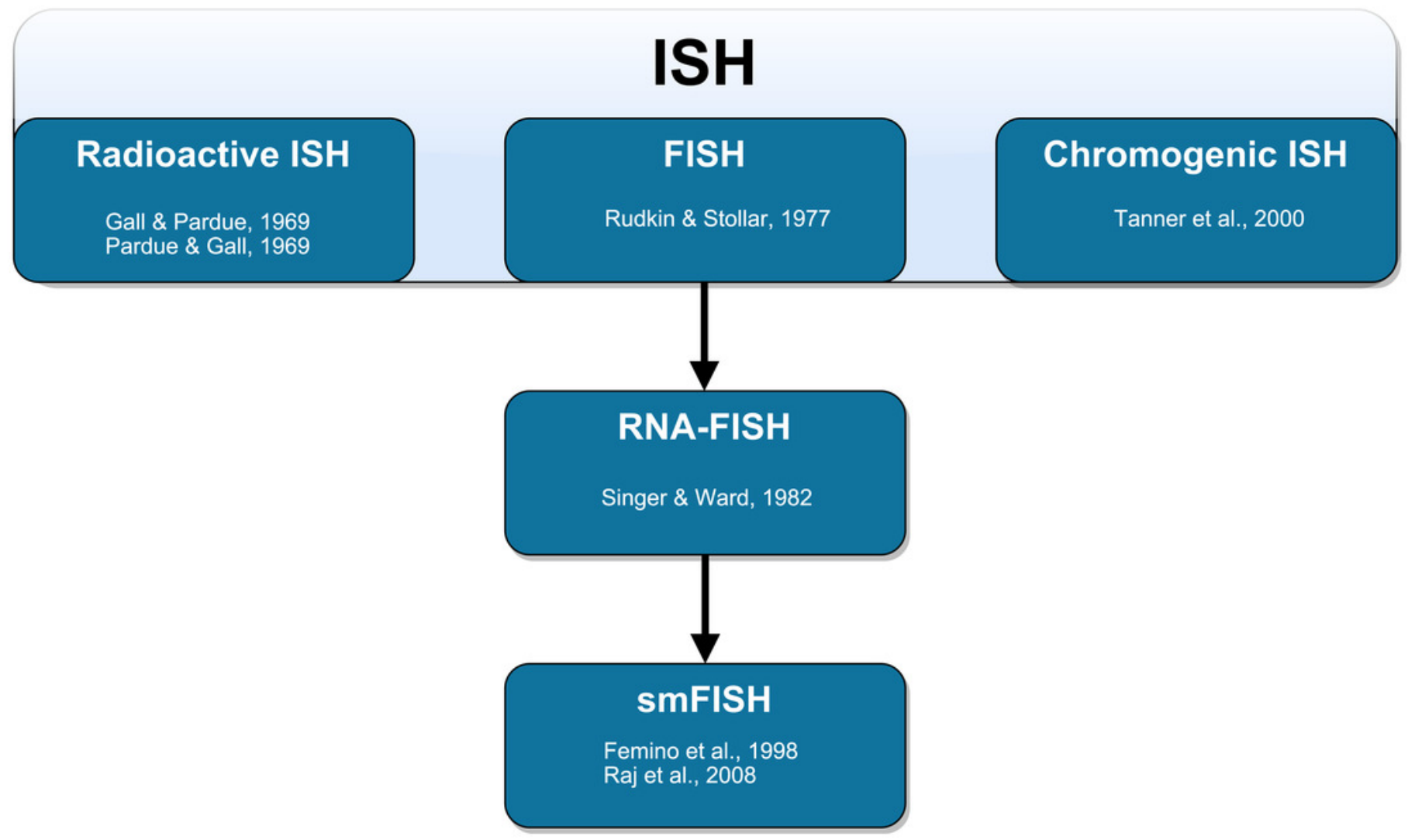


Figure 2

Schematic representation of the riboprobe and oligonucleotide in situ hybridization probe types.

A) Hapten-labeled RNA probes must be bound by an antibody labeled with a fluorophore to allow for visualization. B) DNA oligomers directly labeled with a fluorophore can be directly visualized.

A

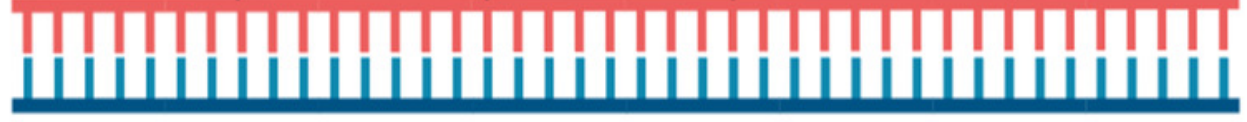

B

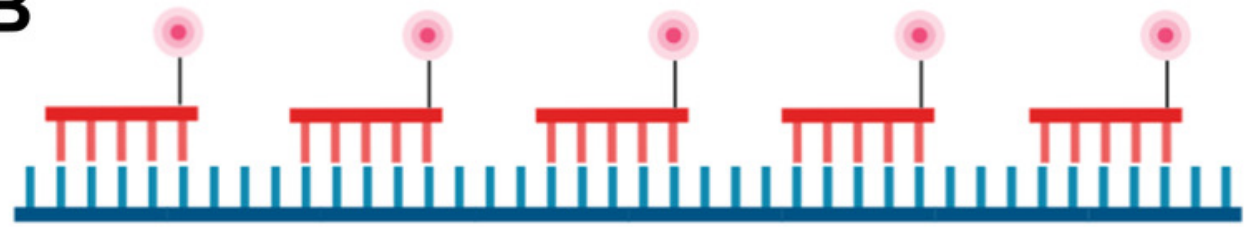

Fluorophore

Antibody

Hapten

TITT Probe mRNA

ШШ Target mRNA 